\title{
Disparity in circulating adiponectin multimers between term and preterm infants*
}

\author{
Tania Siahanidou ${ }^{1, \star \star}$, Alexandra Margeli², \\ Maria Garatzioti ${ }^{1}$, Maria Davradou', Filia \\ Apostolakou'2, loannis Papassotiriou ${ }^{2}$ \\ and Helen Mandyla1 \\ ${ }^{1}$ Neonatal Unit, First Department of Pediatrics, Athens \\ University Medical School, Athens, Greece \\ 2 Department of Clinical Biochemistry, "Aghia Sophia" \\ Children's Hospital, Athens, Greece
}

\begin{abstract}
Aims: To study circulating levels and distribution of adiponectin multimers [low molecular weight (LMW)-, medium molecular weight (MMW)- and high molecular weight (HMW)-adiponectin] in preterm and full-term infants.

Methods: Total serum adiponectin and its multimers were measured in 40 healthy infants at the age of one month and associations with anthropometric parameters [body weight and length, body mass index (BMI)], weight gain and metabolic indices (glucose, insulin) were examined. Twenty of the infants were born preterm (gestational age $33.2 \pm 1.6$ weeks).

Results: LMW-adiponectin level and its fractional ratio to total adiponectin were significantly higher in full-term than in preterm infants $(P<0.001$ and $P<0.01$, respectively), whereas, MMW-adiponectin level and its ratio were significantly lower $(P=0.03$ and $P=0.01$, respectively). HMW-adiponectin did not differ significantly between full-term and preterm infants and accounted for almost $60 \%$ of total adiponectin levels in both groups. HMW-adiponectin, but not MMW adiponectin or LMW adiponectin, correlated significantly with anthropometric measurements, similarly to total adiponectin; in addition, HMW adiponectin correlated significantly with weight gain.
\end{abstract}

*Grant/funding support: Adiponectin reagents provided by BUEHLMANN Laboratories AG, Basel, Switzerland to Dr loannis Papassotiriou. The company played no role in the study design; in the collection, analysis, and interpretation of data; in the writing of the manuscript; and in the decision to submit the manuscript for publication.

${ }^{*}$ Corresponding author:

Tania Siahanidou

Neonatal Unit

First Department of Pediatrics

Athens University Medical School

"Aghia Sophia" Children's Hospital

11527 Athens

Greece

Tel.: +302107467889

Fax: +30 2107759167

E-mail: neonat5@paidon-agiasofia.gr; siahan@med.uoa.gr
Conclusions: HMW adiponectin is the most prevalent form in infants. Circulating levels and distribution of MMW- and LMW-adiponectin differ between full-term and preterm infants, but the role of these adiponectin multimers needs to be studied further.

Keywords: Adiponectin; infants; molecular weight; multimers.

\section{Introduction}

Adiponectin, an adipocytokine with profound insulin-sensitizing effects and important role in regulating systemic energy metabolism [15], circulates in human blood as multimers with distinct molecular sizes: trimeric low molecular weight (LMW)-adiponectin, hexameric medium molecular weight (MMW)-adiponectin, and high molecular weight (HMW)-adiponectin [33]. It has been suggested that adiponectin complexes have different biological activities [23,33], but their specific properties are not yet fully understood. Studies in adults and obese children indicated that HMW-adiponectin is the major active form of this adipokine [2, 3, 9].

A great body of evidence suggests that circulating levels of total adiponectin (composed of the sum of adiponectin complexes), are much higher in neonates and infants than levels in children and adults [16, 24]. Yet, numerous previous studies have documented positive correlations between total adiponectin levels and neonatal anthropometric indices [16, 24, 28, 30, 32]. Thus, it has been strongly suggested that adiponectin has a role in fetal and neonatal growth. However, the adiponectin complexes in neonates have not been studied extensively. Circulating HMW-adiponectin has been evaluated almost exclusively in cord blood of full-term newborns [10, 12, 13, 21], whereas limited knowledge exists regarding $\mathrm{MMW}$-adiponectin and $\mathrm{LMW}$-adiponectin in either preterm or full-term infants [35].

The aim of the present study was to determine the circulating concentrations and distribution of adiponectin complexes in preterm and full-term infants and to examine their possible associations with anthropometric parameters, weight gain and serum levels of glucose and insulin.

\section{Materials and methods}

The study population consisted of 40 healthy infants (20 fullterm and 20 preterm infants with similar gender distribution) who 
met the following criteria: (1) mothers with uncomplicated pregnancy (without gestational diabetes mellitus, thyroid disease, pregnancy-induced hypertension or autoimmune diseases) who had elected formula feeding, (2) no neonatal morbidity (without respiratory distress syndrome, hypotension, intraventricular hemorrhage, necrotizing enterocolitis, sepsis) or congenital malformation, and (3) tolerance of full enteral feeding the first day of life for full-term infants and up to the $7^{\text {th }}$ day of life for preterm infants. Gestational age was estimated from the last menstrual period and confirmed by fetal ultrasound measurements and clinical examination of the neonate according to the new Ballard score [4].

Anthropometric measurements were recorded periodically in all the infants by the same investigator. In preterm infants, body weight was obtained daily using a standard electronic scale. Recumbent length and head circumference were measured weekly using a standardized length board and a non-stretchable plastic insertion tape, respectively. In full-term infants, body weight and length and head circumference were measured weekly by the same method applied to preterm infants. Weight gain in $\mathrm{g} / \mathrm{kg} /$ day was estimated weekly in all infants. In addition, body weight Z-scores [standard deviation (SD) scores from the mean after adjustment for gestational age and gender] were evaluated at the end of the first month of age as described previously [29].

All infants underwent a venipuncture in the morning and before feeding at the end of the first month of age for collection of routine blood tests, as well as for determining total adiponectin and its multimers (HMW-, MMW- and LMW-adiponectin), glucose and insulin in serum.

The study protocol was approved by the Ethics Committee of "Aghia Sophia" Children's Hospital and informed parental consent was also obtained for all infants.

Total adiponectin, HMW-, MMW-, and LMW-adiponectin levels were determined by a sandwich enzyme-linked immunosorbent assay (ELISA) using a commercially available multimeric adiponectin kit (Buehlmann Laboratories AG, Switzerland, produced by Daiichi Pure Chemicals Co, Ltd, Tokyo, Japan). Details of the assay have been described previously [8]. The specific antibodies used in this kit were monoclonal anti-human adiponectin antibodies directed to two independent epitopes. For total adiponectin determination, specimens were treated with sodium dodecyl sulphate (SDS)-containing acid buffer to convert multimeric adiponectin to dimmeric and monomeric forms that were assayed directly on the plate. To measure the HMW-, MMW-, and LMW-adiponectin separately, samples were enzyme pretreated with two proteases, according to manufacturer instructions. For the HMW-adiponectin determination, protease II that selectively digests LMW- and MMW-adiponectin was used and the remaining HMW-adiponectin fraction was treated with SDScontaining acid buffer to convert it mainly to dimmeric and monomeric forms that were assayed directly on the plate [8]. Protease I that selectively digests only the LMW-adiponectin was used for MMW + HMW-adiponectin determination [8]. The concentrations of MMW- and LMW-adiponectin were obtained by subtracting the HMW concentration from the MMW + HMW concentrations and the MMW + HMW concentrations from the total adiponectin concentration, respectively. The intra-assay precision coefficients of variation (CVs) for total-, HMW-, and $\mathrm{MMW}+\mathrm{HMW}$-adiponectin were $<5.4 \%, 5.0 \%$ and $5.0 \%$, respectively, and the inter-assay CVs were $<5.0 \%, 5.7 \%$ and $6 \%$, respectively, at different adiponectin levels, according to the commercially available kit. The limit of sensitivity of the assay was $<0.08 \mathrm{ng} / \mathrm{mL}$.

Serum glucose was assessed by an enzymatic glucose oxidase method and the determination was performed using the Siemens Advia 1800 Clinical Chemistry System (Siemens Healthcare Diagnostics, Erlangen, Germany). The intra- and inter-assay CVs were $<0.9 \%$ and $<1.5 \%$, respectively. Serum insulin concentrations were assessed by an electrochemiluminesce immunoassay using the automated analyzer Cobas e 411 (Roche Diagnostics GmbH, Mannheim, Germany). This assay for insulin determination employs two monoclonal antibodies which together are specific for human insulin. The intra- and interassay CVs did not exceed $2 \%$ and $2.8 \%$, respectively.

Data are presented as mean (SD), apart from insulin concentrations expressed as median ( $25^{\text {th }}-75^{\text {th }}$ percentiles) because of a non-normal distribution. Groups were compared for quantitative variables by the Student- $t$ or Mann-Whitney U-test, as appropriate. Values of adiponectin multimers were normally distributed, both overall and for preterm and full-term infants separately. Correlation analyses were used to examine relations among the variables of interest. Statistical significance was set at $\mathrm{P}<0.05$. All statistical analyses were performed using the SPSS statistical package (SPSS, version 12.0, Chicago, IL).

\section{Results}

Demographic characteristics, anthropometric and growth measurements of the study population are shown in Table 1. Mean (SD) serum glucose concentrations were significantly higher in full-term $[4.9(0.6) \mathrm{mmol} / \mathrm{L}]$ than in preterm infants $[3.9(0.8) \mathrm{mmol} / \mathrm{L}, \mathrm{P}<0.01]$. Median $\left(25^{\text {th }}-75^{\text {th }}\right.$ percentiles) insulin concentrations were also higher in full-term $[6.9(4.1-12.1) \mathrm{mU} / \mathrm{L}]$ than in preterm infants [2.8 (1.2-15.2) $\mathrm{mU} / \mathrm{L}, \mathrm{P}<0.05]$.

Serum levels of total- and LMW-adiponectin were significantly higher in full-term [46.6 (13.2) $\mu \mathrm{g} / \mathrm{mL}$ and 11.7 (7.1) $\mu \mathrm{g} / \mathrm{mL}$, respectively] than in preterm infants [38.1 (11.2) $\mu \mathrm{g} / \mathrm{mL} ; \mathrm{P}=0.03$ and 3.0 (2.5) $\mu \mathrm{g} / \mathrm{mL} ; \mathrm{P}<0.001$, respectively], whereas, levels of $\mathrm{MMW}$-adiponectin were lower [6.3 (4.5) $\mu \mathrm{g} / \mathrm{mL}$ in full-term and 10.5 (7.4) $\mu \mathrm{g} / \mathrm{mL}$ in preterm infants; $P=0.03$ ]. No difference was found in HMW-adiponectin levels between full-term and preterm infants [28.9 (10.3) $\mu \mathrm{g} / \mathrm{mL}$ and 25.0 (7.2) $\mu \mathrm{g} / \mathrm{mL}$, respectively]. In addition, the fractional HMW-adiponectin relative to total-adiponectin levels did not differ significantly between full-term and preterm infants (Figure 1). However, the ratio of $\mathrm{MMW}$-adiponectin to total-adiponectin was lower in full-term than in preterm infants $(P=0.01)$, whereas the ratio of LMW-adiponectin to total adiponectin level was significantly higher $(P<0.01)$ (Figure 1$)$. There was no difference both in absolute values of adiponectin multimers and in their ratios to the total-adiponectin value between sexes in full-term and preterm infants.

HMW-adiponectin levels correlated significantly with total-adiponectin levels in both full-term $(r=0.87$, 
Table 1 Characteristics of preterm and full-term infants.

\begin{tabular}{lll}
\hline & $\begin{array}{l}\text { Preterm infants } \\
(\mathrm{n}=20)\end{array}$ & $\begin{array}{l}\text { Full-term infants } \\
(\mathrm{n}=20)\end{array}$ \\
\hline Gestational age & $33.2(1.6)$ & $39.1(1.2)^{\star \star}$ \\
Birthweight & $1646(280)$ & $3269(334)^{\star \star}$ \\
Males/females & $11 / 9$ & $11 / 9$ \\
Data of studied groups when blood samples were drawn & & \\
Postnatal age, days & $26.0(5.7)$ & $27.3(4.9)$ \\
Body weight, g & $2172(190)$ & $4148(441)^{\star \star}$ \\
Body weight Z-score & $-1.5(0.7)$ & $1.2(0.8)^{\star *}$ \\
Body length, cm & $46.6(1.8)$ & $55.4(2.9)^{\star \star}$ \\
Head circumference, cm & $32.7(1.3)$ & $36.7(1.0)^{\star \star}$ \\
BMl, kg/m² & $10.0(0.8)$ & $13.5(1.0)^{\star \star}$ \\
Weight gain, g/kg/day (last week of study) & $15.5(3.7)$ & $10.5(4.5)^{\star \star}$ \\
\hline
\end{tabular}

All the data except for gender represent the mean (SD). BMI = body mass index. ${ }^{\star \star}$ Compared with preterm infants; ${ }^{\star \star} \mathrm{P} \leq 0.01$.

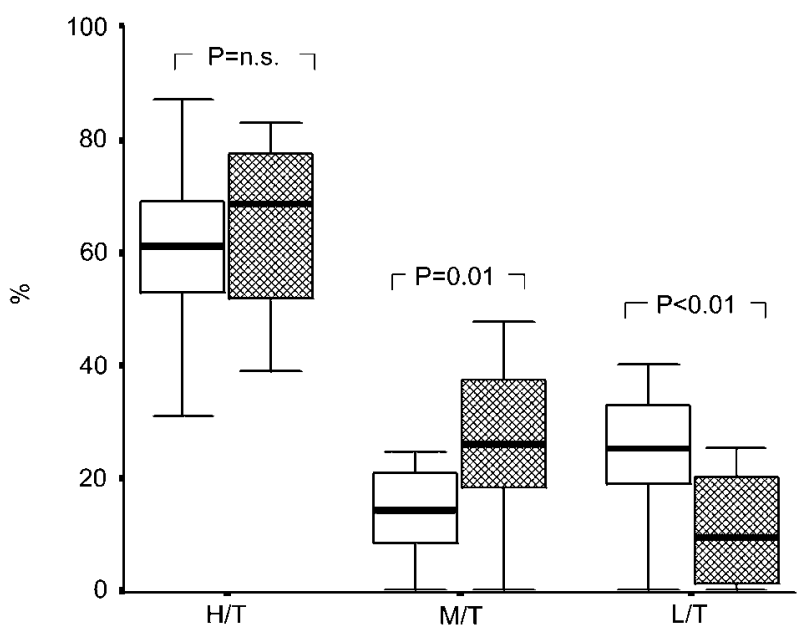

Figure 1 Boxplots showing the fractional ratios of serum adiponectin multimers to total adiponectin in full-term (white boxes) and preterm infants (shaded boxes). Boxes represent the interquartile range; lines inside boxes represent the median value; whiskers represent the lowest and highest observations, respectively. $\mathrm{T}=$ total adiponectin, $\mathrm{H}=\mathrm{HMW}$-adiponectin, $\mathrm{M}=\mathrm{MMW}$ adiponectin, $\mathrm{L}=\mathrm{LMW}$-adiponectin.
$\mathrm{P}<0.001)$ and preterm infants $(r=0.77, \mathrm{P}<0.001)$. A significant correlation between MMW-adiponectin and totaladiponectin levels was observed in preterm infants only $(r=0.93, P<0.001)$, whereas, LMW-adiponectin correlated significantly with total-adiponectin levels in full-term infants only $(r=0.67, P=0.001)$.

In the total study population, HMW-adiponectin levels correlated significantly with birth weight and anthropometric measurements when blood samples were drawn, including body weight, body weight Z-score and body mass index (BMI), similarly to total adiponectin (Table 2). In addition, HMW-adiponectin levels correlated significantly with the infants' weight gain, whereas, a non-significant correlation was recorded between total adiponectin and weight gain $(P=0.08)$. As shown in Table 2, HMW-adiponectin presented all the significant associations observed between total adiponectin and variables studied in preterm and full-term infants separately. MMW-adiponectin and LMW-adiponectin did not correlate significantly with anthropometric measurements or weight gain in the total study population or in the groups of full-term and preterm infants. No significant correlation was also recorded between total adiponectin

Table 2 Correlations between total-adiponectin or HMW-adiponectin levels and anthropometric measurements and weight gain in infants studied.

\begin{tabular}{|c|c|c|c|c|c|c|}
\hline & \multicolumn{2}{|c|}{$\begin{array}{l}\text { Entire study population } \\
(\mathrm{n}=40)\end{array}$} & \multicolumn{2}{|c|}{$\begin{array}{l}\text { Preterm infants } \\
(n=20)\end{array}$} & \multicolumn{2}{|c|}{$\begin{array}{l}\text { Full-term infants } \\
(\mathrm{n}=20)\end{array}$} \\
\hline & vs. Total & vs. HMW & vs. Total & vs. HMW & vs. Total & vs. HMW \\
\hline Birthweight & $0.46^{\star *}$ & $0.36^{\star}$ & $0.67^{\star \star}$ & $0.68^{\star \star}$ & n.s. & n.s. \\
\hline Body weight & $0.38^{*}$ & $0.33^{*}$ & $0.52^{*}$ & $0.77^{\star \star}$ & n.s. & n.s. \\
\hline Body weight Z-score & $0.47^{\star \star}$ & $0.36^{\star}$ & $0.66^{\star \star}$ & $0.61^{\star *}$ & n.s. & n.s. \\
\hline BMI & $0.46^{\star \star}$ & $0.40^{*}$ & $0.60^{*}$ & $0.69^{* \star}$ & $0.78^{\dagger}$ & $0.58^{*}$ \\
\hline Weight gain & n.s. & $0.37^{\star \star}$ & n.s. & $0.64^{\star *}$ & n.s. & $0.67^{\dagger}$ \\
\hline
\end{tabular}

$\mathrm{HMW}=$ high molecular weight, $\mathrm{BMI}=$ body mass index, n.s. = not significant, ${ }^{*} \mathrm{P}<0.05,{ }^{* *} \mathrm{P} \leq 0.01,{ }^{\mathrm{t}} \mathrm{P} \leq 0.001$. 
or any of the adiponectin complexes and glucose or insulin concentrations.

\section{Discussion}

According to the results of this study, there are some differences in level and distribution of adiponectin complexes between full-term and preterm infants. The circulating levels of MMW-adiponectin and their ratio to total-adiponectin levels were significantly lower in fullterm than in preterm infants, but levels of LMW-adiponectin and their proportion were higher. However, HMW-adiponectin levels did not differ significantly between full-term and preterm infants; they accounted for almost $60 \%$ of total-adiponectin levels in both groups. Total adiponectin levels were significantly lower in preterm than in full-term infants, in agreement with previous studies [28]; this difference was probably due to decreased adiposity of preterm infants. There is evidence that circulating adiponectin levels correlate positively with the degree of adiposity in neonates, but negatively in adults [16, 24, 32]. The daily intake of dietary longchain polyunsaturated fatty acids that might have influenced the total adiponectin levels [29] did not differ significantly between the two infant groups (data not shown). In addition, there was no difference in gender distribution between groups. A sex dimorphism in circulating adiponectin levels, with lower levels in males than females, has been described in adulthood [20], in utero $[6,14]$ and in childhood, especially during the progression of puberty [1, 7, 22], and has been attributed to direct or indirect effects of sex hormones on adiponectin secretion from adipocytes [1, 7, 11, 14, 20, 22]. However, gender differences in adiponectin levels were not present in several studies in neonates $[10,16,24,28,32]$ and in our study as well.

To our knowledge, all the three forms of adiponectin multimers have been determined in both full-term and preterm infants only in the recent study of Yoshida et al. [35]. In that study, serum total adiponectin and its multimers were measured in 46 preterm infants at birth and at corrected term postmenstrual age, and in 26 full-term infants at birth [35]. Serum concentrations of total-, HMW-, MMW-, and LMW-adiponectin were significantly greater in full-term than preterm infants at birth, but similar to those of preterm infants at corrected term. The ratio of $\mathrm{HMW}$-adiponectin to total-adiponectin was $\sim 60 \%$ in full-term newborns, in agreement with our findings and with previous studies [12, 13, 21]. However, a direct comparison of the results of the study of Yoshida et al. [35] with ours cannot be done due to differences in study population, especially regarding the postnatal age and the anthropometric measurements of full-term infants.
It is difficult to explain the meaning of the observed differences in levels and proportions of MMW- and LMWadiponectin between preterm and full-term infants. It has been shown that the distribution of adiponectin multimers is influenced by environmental factors, such as acidic conditions and concentrations of calcium, glucose, and testosterone [5, 27, 34], as well as genetic factors, such as mutations of adiponectin associated with impaired multimerization [33]. Adiponectin multimer composition is affected by alterations in posttranslational modifications of adiponectin in response to environmental factors during its production and/or secretion by adipose tissue [25, 26]. However, once synthesized and secreted, the adiponectin multimers circulate as biochemically distinct and stable entities with little evidence of interchange between the different forms [27]. In our view, it would be interesting to ascertain whether the pattern of adiponectin multimer distribution observed in preterm infants reflects a particular distribution of adiponectin multimers in fetal life before term and/or is related to differences in subcutaneous or brown adipose tissue between full-term and preterm infants [31].

The physiological role of human adiponectin multimers is of special interest. In previous studies in adults and obese children, HMW-adiponectin has been reported to correlate inversely with anthropometric measurements (body weight or BMI, waist girth, visceral adipose tissue), metabolic parameters (insulin and homeostasis model of assessment of insulin resistance) and the development of the metabolic syndrome better than plasma total adiponectin levels [2, 9, 17]. In contrast, weak or absent correlations between MMW- or LMW-adiponectin and the above-mentioned parameters have been reported $[18,19]$. Thus, the effects of the MMW- and LMW-adiponectin are still unclear, whereas HMW-adiponectin is believed to be the primary active form having similar biological roles to those recognized, so far, for total adiponectin [2, 3, 9, 19]. In previous studies of HMWadiponectin in cord blood, it has been suggested that HMW-adiponectin has a role on fetal or neonatal growth because it correlated positively with neonatal anthropometric parameters [12, 13].

In our study, HMW-adiponectin did not correlate with metabolic parameters (glucose, insulin), contrary to previous studies in older children and adults [2, 9, 17] but in accordance with other studies in neonates [12, 32]. HMW-adiponectin was the only multimer of adiponectin exerting significant associations with the infants' anthropometric measurements and growth rates and the one that correlated with the variables that total adiponectin was associated with. Further studies are needed to elucidate if $\mathrm{HMW}$-adiponectin is indeed the active form of adiponectin and to evaluate the biological role of MMWand LMW-adiponectin multimers in preterm and full-term infants. 


\section{References}

[1] Andersen KK, Frystyk J, Wolthers OD, Heuck C, Flyvbjerg A. Gender differences of oligomers and total adiponectin during puberty: a cross-sectional study of 859 Danish school children. J Clin Endocrinol Metab. 2007;92:185762.

[2] Araki S, Dobashi K, Kubo K, Asayama K, Shirahata A. High molecular weight, rather than total, adiponectin levels better reflect metabolic abnormalities associated with childhood obesity. J Clin Endocrinol Metab. 2006;91:5113-6.

[3] Aso Y, Yamamoto R, Wakabayashi S, Uchida T, Takayanagi $\mathrm{K}$, Takebayashi K, et al. Comparison of serum high-molecular weight $(\mathrm{HMW})$ adiponectin with total adiponectin concentrations in type 2 diabetic patients with coronary artery disease using a novel enzyme-linked immunosorbent assay to detect HMW adiponectin. Diabetes. 2006;55: 1954-60.

[4] Ballard JL, Khoury JC, Wedig K, Wang L, Eilers-Walsman BL, Lipp R. New Ballard Score, expanded to include extremely premature infants. J Pediatr. 1991;119:417-23.

[5] Banga A, Bodles AM, Rasouli N, Ranganathan G, Kern PA, Owens RJ. Calcium is involved in formation of high molecular weight adiponectin. Metab Syndr Relat Disord. 2008; 6:103-11.

[6] Basu S, Laffineuse L, Presley L, Minium J, Catalano PM, Hauguel-de Mouzon S. In utero gender dimorphism of adiponectin reflects insulin sensitivity and adiposity of the fetus. Obesity (Silver Spring). 2009; [Epub ahead of print].

[7] Bottner A, Kratzsch J, Muller G, Kapellen TM, Bluher S, Keller E, et al. Gender differences of adiponectin levels develop during the progression of puberty and are related to serum androgen levels. J Clin Endocrinol Metab. 2004; 89:4053-61.

[8] Ebinuma H, Miyazaki O, Yago H, Hara K, Yamauchi T, Kadowaki T. A novel ELISA system for selective measurement of human adiponectin multimers by using proteases. Clin Chim Acta. 2006;372:47-53.

[9] Hara K, Horikoshi M, Yamauchi T, Yago H, Miyazaki O, Ebinuma $\mathrm{H}$, et al. Measurement of the high-molecular weight form of adiponectin in plasma is useful for the prediction of insulin resistance and metabolic syndrome. Diabetes Care. 2006;29:1357-62.

[10] Hibino S, Itabashi K, Nakano Y, Inoue M, Tanaka D, Maruyama T. Longitudinal changes in high molecular weight serum adiponectin levels in healthy infants. Pediatr Res. 2009;65:363-6.

[11] Horenburg S, Fischer-Posovszky P, Debatin KM, Wabitsch $M$. Influence of sex hormones on adiponectin expression in human adipocytes. Horm Metab Res. 2008;40:779-86.

[12] Ibanez L, Sebastiani G, Lopez-Bermejo A, Diaz M, LopezBermejo A, Gomez-Roig MD, et al. Gender specificity of body adiposity and circulating adiponectin, visfatin, insulin and IGF-I at term birth: relation to prenatal growth. J Clin Endocrinol Metab. 2008;93:2774-8.

[13] Inoue M, Itabashi K, Nakano Y, Nakano Y, Tobe T. Highmolecular-weight adiponectin and leptin levels in cord blood are associated with anthropometric measurements at birth. Horm Res. 2008;70:268-72.

[14] Kajantie E, Hytinantti T, Hovi P, Andersson S. Cord plasma adiponectin: a 20 -fold rise between 24 weeks gestation and term. J Clin Endocrinol Metab. 2004;89:4031-6.
[15] Karbowska J, Kochan Z. Role of adiponectin in the regulation of carbohydrate and lipid metabolism. J Physiol Pharmacol. 2006;57:103-13.

[16] Kotani Y, Yokota I, Kitamura S, Matsuda J, Naito E, Kuroda Y. Plasma adiponectin levels in newborns are higher than those in adults and positively correlated with birth weight. Clin Endocrinol. 2004;61:418-23.

[17] Lara-Castro C, Luo N, Wallace P, Klein RL, Garvey WT. Adiponectin multimeric complexes and the metabolic syndrome trait cluster. Diabetes. 2006;55:249-59.

[18] Liu Y, Retnakaran R, Hanley A, Tungtrongchitr R, Shaw C, Sweeney $\mathrm{G}$. Total and high molecular weight but not trimeric or hexameric forms of adiponectin correlate with markers of the metabolic syndrome and liver injury in Thai subjects. J Clin Endocrinol Metab. 2007;92:4313-8.

[19] Nishimura R, Morimoto A, Matsudaira T, Miyashita Y, Sano $H$, Shirasawa $T$, et al. Ratio of high-, medium-, and lowmolecular weight serum adiponectin to total adiponectin value in children. J Pediatr. 2007;151:545-7.

[20] Nishizawa H, Shimomura I, Kishida K, Maeda N, Kuriyama $\mathrm{H}$, Nagaretani $\mathrm{H}$, et al. Androgens decrease plasma adiponectin, an insulin-sensitizing adipocyte-derived protein. Diabetes. 2002;51:2734-41.

[21] Odden N, Morkrid L. High molecular weight adiponectin dominates in cord blood of newborns but is unaffected by pre-eclamptic pregnancies. Clin Endocrinol. 2007;67: 891-6.

[22] Ong KK, Frystyk J, Flyvbjerg A, Petry CJ, the Avon Longitudinal Study of Parents and Children Study Team, Ness A, et al. Sex-discordant associations with adiponectin and lipid profiles in children. Diabetes. 2006;55:1337-41.

[23] Pajvani UB, Hawkins M, Combs TP, Rajala MW, Doebber T, Berger JP, et al. Complex distribution, not absolute amount of adiponectin, correlates with thiazolidine-mediated improvement in insulin sensitivity. J Biol Chem. 2004; 279:12152-62.

[24] Pardo IM, Geloneze B, Tambascia MA, Barros-Filho AA. Hyperadiponectinemia in newborns: Relationship with leptin levels and birth weight. Obes Res. 2004;12:521-4.

[25] Peake PW, Hughes JT, Shen Y, Charlesworth JA. Glycosylation of human adiponectin affects its conformation and stability. J Mol Endocrinol. 2007;39:45-52.

[26] Richards AA, Stephens T, Charlton HK, Jones A, Macdonald GA, Prins JB, et al. Adiponectin multimerization is dependent on conserved lysines in the collagenous domain: Evidence for regulation of multimerization by alterations in posttranslational modifications. Mol Endocrinol. 2006;20:1673-87.

[27] Schraw T, Wang ZV, Halberg N, Hawkins M, Scherer PE. Plasma adiponectin complexes have distinct biochemical characteristics. Endocrinology. 2008;149:2270-82.

[28] Siahanidou T, Mandyla H, Papassotiriou GP, Papassotiriou I, Chrousos G. Circulating levels of adiponectin in preterm infants. Arch Dis Child Fetal Neonat Ed. 2007;92:F286-90.

[29] Siahanidou T, Margeli A, Lazaropoulou C, Karavitakis E, Papassotiriou I, Mandyla H. Circulating adiponectin in preterm infants fed long-chain polyunsaturated fatty acids (LCPUFA)-supplemented formula-A randomized controlled study. Pediatr Res. 2008;63:428-32.

[30] Sivan E, Mazaki-Tovi S, Pariente C, Efraty Y, Schieff E, Hemi R, et al. Adiponectin in human cord blood: Relation to fetal birth weight and gender. J Clin Endocrinol Metab. 2003;88:5656-60. 
[31] Thomas EL, Uthaya S, Vasu V, McCarthy JP, McEwan P, Hamilton G, et al. Neonatal intrahepatocellular lipid. Arch Dis Child Fetal Neonatal Ed. 2008;93:F382-3.

[32] Tsai PJ, Yu CH, Hsu SP, Lee YH, Chiou CH, Hsu YW, et al. Cord plasma concentrations of adiponectin and leptin in healthy term neonates: positive correlation with birthweight and neonatal adiposity. Clin Endocrinol. 2004;61: 88-93.

[33] Waki H, Yamauchi T, Kamon J, Ito Y, Uchida S, Kita S, et al. Impaired multimerization of human adiponectin mutants associated with diabetes. J Biol Chem. 2003;278:4035263.

[34] Xu A, Chan KW, Hoo R, Wang Y, Tan K, Zhang J, et al.
Testosterone selectively reduces the high molecular weight form of adiponectin by inhibiting its secretion from adipocytes. J Biol Chem. 2005;280:18073-80.

[35] Yoshida T, Nagasaki H, Asato Y, Ohta T. The ratio of highmolecular weight adiponectin and total adiponectin differs in preterm and term infants. Pediatr Res. 2009;65:580-3.

The authors stated that there are no conflicts of interest regarding the publication of this article.

Received December 17, 2008. Revised April 30, 2009. Accepted June 9, 2009. Previously published online July 10, 2009. 